\title{
Reduction in sputum neutrophil and eosinophil numbers by the PDE4 inhibitor roflumilast in patients with COPD
}

\author{
Diana C Grootendorst, Stefanie A Gauw, Renate M Verhoosel, Peter J Sterk, Jeannette J Hospers, \\ Dirk Bredenbröker, Thomas D Bethke, Pieter S Hiemstra, Klaus F Rabe
}

See end of article for authors' affiliations

Correspondence to: Dr Diana C Grootendorst, Department of Pulmonology C3-P, Leiden University Medical Center, P O Box 9600, 2300 RC Leiden, The Netherlands; d.c.

Grootendorst@lumc.nl

Received 1 December 2006 Accepted 16 May 2007

Published Online First 15 June 2007

\begin{abstract}
Background: Roflumilast is a targeted oral once-daily administered phosphodiesterase 4 (PDE4) inhibitor with clinical efficacy in chronic obstructive pulmonary disease (COPD). Results from in vitro studies with roflumilast indicate that it has anti-inflammatory properties that may be applicable for the treatment of COPD. Methods: In a crossover study, 38 patients with COPD (mean (SD) age 63.1 (7.0) years, post-bronchodilator forced expiratory volume in $1 \mathrm{~s}\left(\mathrm{FEV}_{1}\right) 61.0(12.6) \%$ predicted) received $500 \mu \mathrm{g}$ roflumilast or placebo once daily for 4 weeks. Induced sputum samples were collected before and after 2 and 4 weeks of treatment. Differential and absolute cell counts were determined in whole sputum samples. Markers of inflammation were determined in sputum supernatants and blood. Spirometry was performed weekly.

Results: Roflumilast significantly reduced the absolute number of neutrophils and eosinophils/g sputum compared with placebo by $35.5 \%(95 \% \mathrm{Cl} 15.6 \%$ to $50.7 \%$; $p=0.002)$ and $50.0 \%(95 \% \mathrm{Cl} 26.8 \%$ to $65.8 \%$; $p<0.001$ ), respectively. The relative proportion of sputum neutrophils and eosinophils was not affected by treatment ( $p>0.05$ ). Levels of soluble interleukin- 8 , neutrophil elastase, eosinophil cationic protein and $\alpha_{2}$ macroglobulin in sputum and the release of tumour necrosis factor $\alpha$ from blood cells were significantly reduced by roflumilast compared with placebo treatment ( $p<0.05$ for all). Post-bronchodilator FEV improved significantly during roflumilast compared with placebo treatment with a mean difference between treatments of $68.7 \mathrm{ml}(95 \% \mathrm{Cl} 12.9$ to $124.5 ; \mathrm{p}=0.018)$.

Conclusion: PDE4 inhibition by roflumilast treatment for 4 weeks reduced the number of neutrophils and eosinophils, as well as soluble markers of neutrophilic and eosinophilic inflammatory activity in induced sputum samples of patients with COPD. This anti-inflammatory effect may in part explain the concomitant improvement in post-bronchodilator $\mathrm{FEV}_{1}$.
\end{abstract}

Abbreviations: COPD, chronic obstructive pulmonary disease; $E C P$, eosinophil cationic protein; $\mathrm{FEV}_{1}$, forced expiratory volume in $1 \mathrm{~s} ; \mathrm{FVC}$, forced vital capacity; IL, interleukin; LPS, lipopolysaccharide; PDE, phosphodiesterase; TNF $\alpha$, tumour necrosis factor $\alpha$

lymphocytes and smooth muscle cells also express PDE3. ${ }^{14}$ Roflumilast is a targeted PDE4 inhibitor which is under investigation for the treatment of COPD and bronchial asthma. It ameliorates the activity of various inflammatory cells in vitro $^{15}$ and reduces pulmonary inflammation in complex in vivo animal models. ${ }^{16}{ }^{17}$ Furthermore, roflumilast has clinical effects in patients with COPD. Treatment for 24 weeks improves lung function and reduces the number of mild exacerbations. ${ }^{18}$ However, at present it is unknown whether roflumilast has anti-inflammatory properties in patients with COPD.

A study was therefore undertaken to examine the efficacy of oral roflumilast treatment (500 $\mu \mathrm{g}$ once daily for 4 weeks) compared with placebo on the reduction in the percentage of sputum neutrophils in patients with COPD. Secondary end points examined were the effect of roflumilast versus placebo on $\mathrm{FEV}_{1}$, absolute numbers of neutrophils in sputum, other inflammatory cell numbers and percentages in sputum, and markers of activation of inflammatory cells (IL-8, neutrophil elastase, lactoferrin and eosinophil cationic protein (ECP)) and markers of microvascular leakage $\left(\alpha_{2}\right.$-macroglobulin) in sputum supernatant. In addition, the effect of oral roflumilast on systemic markers of inflammation was studied by measurement of TNF $\alpha$ production by whole blood cultures following lipopolysaccharide (LPS) stimulation and soluble E-selectin levels in serum. the second messenger cyclic adenosine monophosphate (cAMP). ${ }^{12}{ }^{13}$ Raised levels of this second messenger relax airway smooth muscle and modulate inflammatory cell activity. ${ }^{14}$ PDE4 is expressed in inflammatory cells and airway smooth muscle, while basophils, mast cells, monocytes/macrophages, $\mathrm{T}$ 


\section{METHODS}

\section{Patients}

Patients with a history of $\mathrm{COPD}^{1}$ for at least 1 year were invited to participate in the study and had to fulfil the following criteria: age 45-75 years, current smokers or ex-smokers (stable for $\geqslant 6$ months) with a smoking history $\geqslant 10$ pack-years, prebronchodilator $\mathrm{FEV}_{1} / \mathrm{FVC} \leqslant 70 \%$, post-bronchodilator $\mathrm{FEV}_{1} 35-$ $75 \%$ predicted, reversibility in $\mathrm{FEV}_{1}<12 \%$ or $<200 \mathrm{ml}$ from the pre-bronchodilator value, sputum neutrophilia $(\geqslant 45 \%$ nonsquamous cells) and no exacerbation or upper respiratory tract infection during the 4 weeks before the start of the study. Short-acting bronchodilators were allowed during the study whereas long-acting bronchodilators, theophylline (2 weeks), inhaled and/or oral corticosteroids ( 4 weeks) were discontinued prior to inclusion. The study was approved by the medical ethics committee of the Leiden University Medical Center and performed according to the Declaration of Helsinki. ${ }^{2}$ All patients gave written informed consent.

\section{Design}

This randomised, double-blind, placebo-controlled, crossover study consisted of two treatment periods of 4 weeks with a washout period of 4-6 weeks between treatments (fig 1). Following inclusion, patients entered a run-in period of 2 weeks during which placebo tablets were used. Patients compliant to the study medication ( $>70 \%$ of tablets used) and with lung function and sputum within the criteria of inclusion were randomised to receive either roflumilast $500 \mu \mathrm{g}$ or placebo once daily for 4 weeks by means of a concealed computergenerated randomisation list.

During each treatment period, patients visited the laboratory at weekly intervals for measurement of lung function, compliance check and sampling of blood for determination of E-selectin and whole blood stimulation assay with LPS for measuring TNF $\alpha$. Blood samples were drawn at weeks 0 and 8 before administration of medication (total volume $49 \mathrm{ml}$ ), but at all other visits blood was drawn approximately $\mathrm{l} h$ after the intake of study medication (total volume $34.5 \mathrm{ml}$ ). Sputum samples were collected at inclusion in the study, at the start of each treatment period, and after 2 and 4 weeks of treatment. All patients were supplied with a salbutamol metered dose inhaler ( $100 \mu \mathrm{g} / \mathrm{puff}$ ) for on-demand symptom relief. Patients withheld salbutamol, smoking and caffeine-containing beverages for $6 \mathrm{~h}$ and anticholinergic agents for $8 \mathrm{~h}$ before lung function measurements. ECG, vital signs and clinical laboratory parameters were performed at inclusion in the study and at the beginning and end of each treatment period. Adverse events were monitored throughout the study.

\section{Measurements}

$\mathrm{FEV}_{1}$ was recorded from maximal expiratory flow-volume curves on a calibrated pneumotachograph according to standards. ${ }^{19}{ }^{20}$ Reversibility of $\mathrm{FEV}_{1}$ was determined 30 min after inhalation of $400 \mu \mathrm{g}$ salbutamol.
Table 1 Demographic data of patients in the efficacy analysis

\begin{tabular}{ll}
\hline Sex $(M: F)^{*}$ & $29: 9$ \\
Age (years) & $63.1(7.0)$ \\
Smoking history (pack-years)† & $40.0(10-90)$ \\
Smoking status (current:ex)* & $18: 20$ \\
Pre-bronchodilator $\mathrm{FEV}_{1}(\mathrm{I})$ & $1.79(0.60)$ \\
Pre-bronchodilator $\mathrm{FEV}_{1}$ (\% predicted) & $57.9(12.9)$ \\
Post-bronchodilator $\mathrm{FEV}_{1}$ (\% predicted) & $61.0(12.6)$ \\
Reversibility (\% from pre-bronchodilator & $6.0(6.0)$ \\
$\mathrm{FEV}_{1}$ ) & \\
Pre-bronchodilator $\mathrm{FEV}_{1} / \mathrm{FVC}(\%)$ & $54.4(10.1)$ \\
\hline
\end{tabular}

$\mathrm{FEV}_{1}$, forced expiratory volume in $1 \mathrm{~s}$; FVC, forced vital capacity.

Data are mean (SD) unless otherwise indicated.

*Numbers.

†Median (minimum - maximum)

Sputum induction was performed by inhalation of $4.5 \%$ hypertonic saline aerosols. ${ }^{21}$ Whole sputum samples were processed.22 Differential cell counts were expressed as the percentage of non-squamous cells. Absolute cell numbers were calculated as ( $\%$ cell $\times$ total cell count)/sputum weight. IL- 8 , lactoferrin, $\alpha_{2}$-macroglobulin ${ }^{23}$ and neutrophil elastase were measured by enzyme-linked immunosorbent assays (ELISA) and ECP was measured by fluoroimmunoassay. E-selectin concentrations in serum were measured by ELISA. TNF $\alpha$ release was assessed in whole blood cultures of heparinised blood stimulated with LPS, essentially as described. ${ }^{24}$

\section{Safety}

This trial involved extensive safety and tolerability assessments including vital signs, clinical, laboratory and adverse event monitoring.

\section{Statistical analysis}

Demographic data are presented as mean (SD) or median (minimum, maximum). Non-normally distributed data were log-transformed before analysis. The primary end point of the study was the reduction in the percentage of sputum neutrophils. Further analyses included $\mathrm{FEV}_{1}$, absolute number of sputum neutrophils, other inflammatory cell numbers and percentages in sputum, markers of activation of inflammatory cells (IL-8, neutrophil elastase, lactoferrin and ECP), markers of microvascular leakage ( $\alpha_{2}$-macroglobulin) in sputum supernatant, and systemic markers of inflammation including TNF $\alpha$ production by whole blood cultures following LPS stimulation and soluble E-selectin levels in serum. The sample size was calculated using a two-sided $\alpha$ of $5 \%$ and a power of $80 \%$, together with a conservative estimation of the correlation between paired observations (0.5). It was calculated that, with a sample size of 32 (evaluable) patients, we would be able to detect a treatment effect with a standard deviation of 1.9 times the mean difference. Longitudinal data were analysed by



Figure 1 Following a 2-week run-in period, patients were randomised to receive roflumilast ( $500 \mu \mathrm{g}$ once daily) or matching placebo for a period of 4 weeks. Four to 6 weeks after washout of the medication of the first treatment period, patients crossed over to the alternative treatment. During each treatment period, patients visited the department on a weekly basis. LF, lung function measurement by spirometry; rev, reversibility testing of forced expiratory volume in $1 \mathrm{~s}\left(\mathrm{FEV}_{1}\right)$ with $400 \mu \mathrm{g}$ salbutamol. 


\begin{tabular}{|c|c|c|c|}
\hline & $\%$ & $\times 10^{5}$ cells $/ g$ sputum & Concentration \\
\hline \multicolumn{4}{|l|}{ Induced sputum } \\
\hline Total non-squamous cells & _- & $18.0(2.0-87.1)+$ & \\
\hline Squamous cells & $10.7(0-74.4)$ & & \\
\hline Neutrophils & $74.4(46.4-95.4)$ & $13.0(1.7-84) t$ & \\
\hline Macrophages & $20.5(2.6-47.6)$ & $3.2(0.2-21.1) \dagger$ & \\
\hline Eosinophils & $0.8(0.02-8.0) t$ & $0.14(0.001-4.2) \dagger$ & \\
\hline Lymphocytes & $1.4(0-4.6)$ & $0.24(0.024-1.87) \dagger$ & \\
\hline \multicolumn{4}{|l|}{ Markers in sputum supernatant } \\
\hline IL-8 (ng/ml) & & & $12.5(0.49-179.9) \dagger$ \\
\hline Neutrophil elastase $(\mu \mathrm{g} / \mathrm{ml})$ & & & $3.61(0.14-120.3) \dagger$ \\
\hline Lactoferrin $(\mu \mathrm{g} / \mathrm{ml})$ & & & $73.5(0.8-512.9) t$ \\
\hline ECP $(\mu \mathrm{g} / \mathrm{l})$ & & & $170.8(15.6-5767.5)+$ \\
\hline$\alpha_{2}$-macroglobulin ( $\mathrm{ng} / \mathrm{ml}$ ) & & & $1345.7(20.1-15063.04) \dagger$ \\
\hline \multicolumn{4}{|l|}{ Blood } \\
\hline E-selectin ( $\mathrm{ng} / \mathrm{ml})$ & & & $51.7(33.5-94.6) \dagger$ \\
\hline $\mathrm{TNF} \alpha(\mathrm{ng} / \mathrm{ml})$ & & & $8.1(1.6-37.0) \dagger$ \\
\hline
\end{tabular}

IL, interleukin; ECP, eosinophil cationic protein; TNF $\alpha$, tumour necrosis factor $\alpha$.

Data are median or tgeometric mean (minimum - maximum).

repeated measures analysis with a correction for period effects (ANCOVA). Effect estimates between treatments were calculated from linear mixed models and presented as point estimates with 95\% confidence intervals. Confidence intervals of point estimates not including 1 for log-transformed data and not including 0 for normally distributed data were interpreted as statistically significant. A p value of $<0.05$ was considered significant for the latter analyses.

\section{RESULTS}

\section{Participants}

Forty-four patients with COPD were included in the study between January 2001 and March 2002, 41 of whom were randomised. In two patients $\mathrm{FEV}_{1}$ reversibility criteria were not met and in one patient the neutrophilia criteria were not met. These patients were excluded from the analyses. Data from a total of 38 patients were therefore used for the efficacy analysis. Six patients dropped out of the study during treatment for the following reasons: withdrawal of consent $(n=1)$, exacerbation of COPD requiring additional treatment $(n=2)$, and adverse events to the study medication $(\mathrm{n}=3$, see below). The baseline characteristics of the patients who contributed to the efficacy analysis are shown in tables 1 and 2.

\section{Lung function}

Pre- and post-bronchodilator $\mathrm{FEV}_{1}$ improved significantly during roflumilast treatment (fig 2). The change in both pre- and post-bronchodilator $\mathrm{FEV}_{1}$ was significantly different between roflumilast and placebo treatment (fig 2, p $<0.0001$ and $\mathrm{p}=0.018$, respectively). The point estimate of difference between the treatments was $79.5 \mathrm{ml}$ (95\% confidence interval (CI) 54.0 to 105.1) for pre-bronchodilator $\mathrm{FEV}_{1}$ and $68.7 \mathrm{ml}$ (95\% CI 12.9 to 124.5 ) for post-bronchodilator $\mathrm{FEV}_{1}$.

\section{Inflammatory cells in sputum}

At baseline the total inflammatory cell count comprised primarily neutrophils (74\%). The inflammatory cell load in the airways, as reflected by the total non-squamous cell count in sputum samples, decreased during roflumilast treatment but increased during placebo treatment (difference between treatments $p=0.002$, fig 3 ). Overall, the total cell count decreased significantly by $34 \%$ during roflumilast treatment compared with placebo (table 3 ). In particular, roflumilast treatment was associated with a significant decrease in neutrophil numbers in sputum $(p=0.002$, fig 3 , table 3$)$. In addition, roflumilast treatment reduced sputum eosinophil $(\mathrm{p}<0.001$, fig 3, table 3$)$, macrophage $(p=0.067$, table 3$)$ and lymphocyte numbers $(p=0.022$, table 3$)$. Sputum weight was not affected by roflumilast or placebo treatment $(\mathrm{p}=0.68$, table 3$)$.

In contrast to absolute cell numbers, differential cell counts for neutrophils, macrophages and lymphocytes, expressed as a percentage of total non-squamous cells, were not affected by the treatments (table 3 ). The percentage of eosinophils tended



Figure 3 Change in total cell count and numbers of neutrophils and eosinophils in sputum during roflumilast (black bars) and placebo (white bars) treatment for 4 weeks.

Figure 2 Change in pre- and post-bronchodilator (bd) forced expiratory volume in $1 \mathrm{~s}\left(\mathrm{FEV}_{1}\right)$ during roflumilast (black bars) and placebo (white bars) treatment for 4 weeks. 
to be reduced by roflumilast treatment compared with placebo $(\mathrm{p}=0.052$, table 3$)$.

\section{Markers of inflammation and microvascular leakage in sputum supernatant}

The levels of the neutrophil chemoattractant IL-8 and the neutrophil degranulation product neutrophil elastase decreased significantly during roflumilast treatment compared with placebo $(p<0.05$, fig 4 , table 3$)$. In contrast to neutrophil elastase, levels of lactoferrin (a marker of neutrophil activity but also produced by submucosal glands) were not affected during treatment ( $p=0.18$, fig 4 , table 3 ). Eosinophil activity, as reflected by ECP levels in sputum, was significantly reduced by roflumilast treatment compared with placebo $(\mathrm{p}=0.015$, fig 4 , table 3 ). Roflumilast significantly reduced microvascular leakage, as measured by $\alpha_{2}$-macroglobulin, compared with placebo $(\mathrm{p}<0.001$, fig 4 , table 3$)$.

\section{Markers of inflammation in the circulation}

$\mathrm{TNF} \alpha$ secretion by whole blood cultures following ex vivo stimulation by LPS was significantly reduced during roflumilast treatment compared with placebo $(p=0.047$, table 3$)$. In contrast, E-selectin levels in the circulation were not different between the two treatments $(p=0.23$, table 3$)$.

There was no carry-over effect from the first to the second treatment period in any statistical analysis presented.

\section{Adverse events}

Thirty-three patients (87\%) reported at least one adverse event during roflumilast treatment compared with 26 patients $(67 \%)$ during placebo treatment (table 4). These adverse events were of mild or moderate intensity and transient. No serious adverse events were reported. The most frequent adverse events with

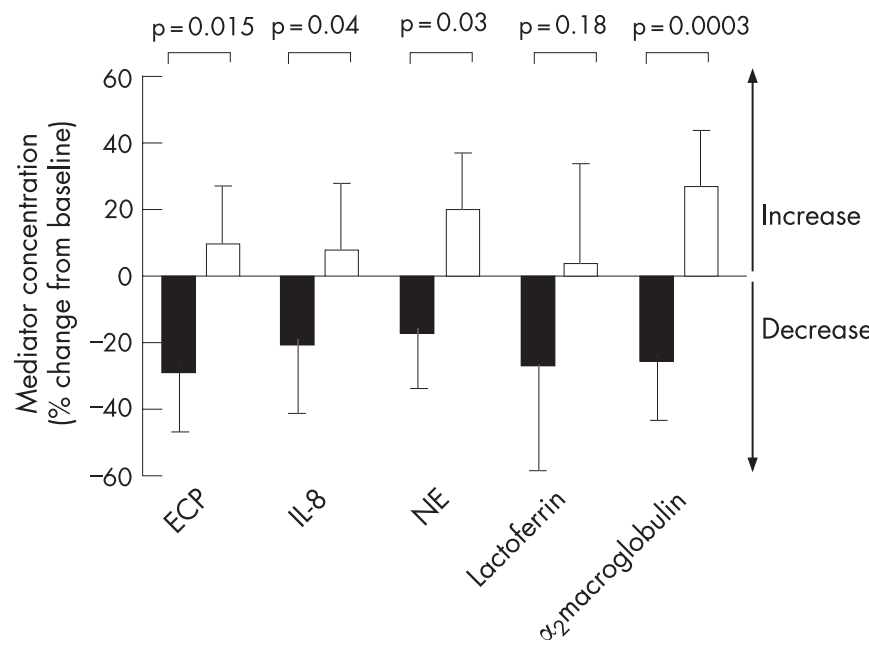

Figure 4 Changes in eosinophil cationic protein (ECP), interleukin (IL)-8 and neutrophil elastase (NE), lactoferrin and $\alpha_{2}$-macroglobulin levels in sputum supernatants during roflumilast (black bars) and placebo (white bars) treatment for 4 weeks.

roflumilast were diarrhoea and headache, which are part of the known side effect profile of this drug. Three patients discontinued the study owing to adverse events, which were all during roflumilast treatment. Their adverse events resolved upon withdrawal of the study medication. There were no relevant findings regarding laboratory, ECG and vital signs.

\section{DISCUSSION}

This crossover placebo controlled study is the first to examine the anti-inflammatory and pulmonary effects of the oral PDE4

\begin{tabular}{|c|c|c|}
\hline & Mean difference $(95 \% \mathrm{Cl})$ & p Value \\
\hline \multicolumn{3}{|l|}{ Sputum characteristics } \\
\hline Total cell count $\left(\times 10^{5}\right.$ cells $\left./ \mathrm{g}\right) \dagger$ & $-33.6 \%(-48.8$ to -13.8$)$ & 0.002 \\
\hline Weight $(\mathrm{g})^{*}$ & $0.15(-0.56$ to 0.86$)$ & 0.68 \\
\hline Viability (\%)* & $-2.0(-4.4$ to 0.3$)$ & 0.091 \\
\hline Squamous cell contamination $(\%)^{*}$ & $-1.8(-6.0$ to 2.5$)$ & 0.41 \\
\hline \multicolumn{3}{|l|}{ Cellular inflammation in sputum } \\
\hline Absolute number of neutrophils $† \ddagger$ & $-35.5 \%(-50.7$ to -15.6$)$ & 0.002 \\
\hline Absolute number of eosinophilstł & $-50.0 \%(-65.8$ to -26.8$)$ & $<0.001$ \\
\hline Absolute number of macrophages $† \ddagger$ & $-24.4 \%(-43.9$ to 2.0$)$ & 0.067 \\
\hline Absolute number of lymphocytes $† \ddagger$ & $-34.8 \%(-54.7$ to -6.1$)$ & 0.022 \\
\hline$\%$ Neutrophils* ${ }^{*}$ T & $-1.6(-4.8$ to 1.6$)$ & 0.31 \\
\hline \% Eosinophils $†$ & $-25.2 \%(-44.3$ to 0.3$)$ & 0.052 \\
\hline \% Macrophages* & $1.8(-0.9$ to 4.6$)$ & 0.19 \\
\hline \% Lymphocytes $\dagger$ & $-4.1 \%(-23.8$ to 20.7$)$ & 0.72 \\
\hline \multicolumn{3}{|c|}{ Markers of inflammation in sputum supernatant } \\
\hline IL-8 (ng/ml)† & $-25.9 \%(-44.7$ to -0.8$)$ & 0.044 \\
\hline Neutrophil elastase $(\mu \mathrm{g} / \mathrm{ml}) \dagger$ & $-30.6 \%(-49.8$ to -4.1$)$ & 0.028 \\
\hline Lactoferrin $(\mu \mathrm{g} / \mathrm{ml}) \dagger$ & $-29.0 \%(-57.3$ to 17.9$)$ & 0.18 \\
\hline $\mathrm{ECP}(\mu \mathrm{g} / \mathrm{l}) \dagger$ & $-34.3 \%(-53.1$ to -7.9$)$ & 0.015 \\
\hline \multicolumn{3}{|c|}{ Markers of microvascular leakage in sputum supernatant } \\
\hline$\alpha_{2}$-Macroglobulin (ng/ml) $\dagger$ & $-40.8 \%(-55.0$ to -22.3$)$ & $<0.001$ \\
\hline \multicolumn{3}{|l|}{ Systemic markers of inflammation } \\
\hline E-selectin $(\mathrm{ng} / \mathrm{ml}) \dagger$ & $-1.7 \%(-4.5$ to 1.1$)$ & 0.23 \\
\hline $\mathrm{TNF} \alpha(\mathrm{pg} / \mathrm{ml}) \dagger$ & $-10.4 \%(-19.7$ to -0.1$)$ & 0.047 \\
\hline \multicolumn{3}{|l|}{ Lung function } \\
\hline Pre-bronchodilator $\mathrm{FEV}_{1}(\mathrm{ml})^{*}$ & $79.5 \mathrm{ml}$ (54.0 to 105.1$)$ & $<0.001$ \\
\hline Post-bronchodilator $\mathrm{FEV}_{1}(\mathrm{ml})^{*}$ & $68.7 \mathrm{ml}$ (12.9 to 124.5$)$ & 0.018 \\
\hline \multicolumn{3}{|c|}{$\begin{array}{l}\text { IL, interleukin; ECP, eosinophil cationic protein; TNF } \alpha \text {, tumour necrosis factor } \alpha \text {; FEV } V_{1} \text {, forced expiratory volume in } 1 \mathrm{~s} \text {. } \\
\text { "Mean difference between treatments represents "absolute" difference between roflumilast and placebo treatment for } \\
\text { sputum weight, viability, squamous cell contamination, percentage of neutrophils and percentage of macrophages in } \\
\text { sputum, and pre- and post-bronchodilator FEV } \\
t^{\prime \prime} \text {. Relative" difference (mean ratio of change from baseline) for total cell count, number of neutrophils, eosinophils, } \\
\text { macrophages and lymphocytes, percentage of eosinophils, percentage of lymphocytes, IL-8, neutrophil elastase, } \\
\text { lactoferrin, ECP, } \alpha_{2} \text {-macroglobulin, E-selectin and TNF } \alpha \text { since these parameters were log-transformed prior to analyses. } \\
\neq \text { Unit of absolute cells in sputum } \times 10^{5} \text { cells } / g \text { sputum. }\end{array}$} \\
\hline
\end{tabular}


Table 4 Number (\%) of patients with adverse events during treatment periods

Roflumilast Placebo

\begin{tabular}{lll}
\hline $\begin{array}{l}\text { Body as a whole (flu syndrome, abdominal pain, } \\
\text { malaise, back pain) }\end{array}$ & $17(45)$ & $10(26)$ \\
$\begin{array}{l}\text { Digestive system (diarrhea, nausea, abnormal } \\
\text { stool, vomiting, dyspepsia) }\end{array}$ & $17(45)$ & $4(10)$ \\
$\begin{array}{l}\text { Nervous system (headache, dizziness) } \\
\text { Respiratory system (increased cough, dyspnoea, }\end{array}$ & $17(45)$ & $2(42)$ \\
$\begin{array}{l}\text { upper respiratory tract infection, rhinitis, } \\
\text { increased sputum production) }\end{array}$ & $15(39)$ \\
$\begin{array}{l}\text { Cardiovascular system (ECG abnormal, chest } \\
\text { pain, palpitation, thrombophlebitis) }\end{array}$ & $4(11)$ & $1(3)$ \\
\hline
\end{tabular}

Adverse events with incidence $\geqslant 1 \%$ are listed.

inhibitor roflumilast in patients with COPD. Our results show that roflumilast treatment reduces the inflammatory activity in induced sputum, a surrogate for airway inflammation. The absolute number of sputum inflammatory cells (including neutrophils, eosinophils and lymphocytes) were reduced by 35$50 \%$ during the 4-week treatment with roflumilast compared with placebo, with a similar tendency for the number of macrophages. As a result, the total cell count was significantly decreased by $34 \%$. Furthermore, this was accompanied by a reduction in the levels of chemoattractant stimuli for neutrophils, cellular activity of eosinophils and neutrophils in sputum, as well as microvascular leakage. Concomitant with these changes in sputum inflammation were a decrease in TNF $\alpha$ release in the blood and an improvement in pulmonary function as assessed by $\mathrm{FEV}_{1}$. We conclude that roflumilast has anti-inflammatory effects in patients with COPD which is accompanied by an improvement in lung function.

Our data extend the findings of Gamble et al who showed that treatment with the PDE4 inhibitor cilomilast for 12 weeks significantly reduced inflammatory cell numbers in bronchial biopsy specimens from patients with COPD. ${ }^{25}$ In the present study, as well as in the study of Gamble et al, treatment with a PDE4 inhibitor did not change the differential cell counts in sputum samples. This may imply that absolute cell numbers rather than relative cell counts should be assessed to monitor anti-inflammatory effects of treatment in patients with COPD, as has been suggested previously. ${ }^{26}$ Furthermore, we have shown that roflumilast significantly attenuates cellular activity within the airways of patients with COPD, as reflected by reductions in the level of IL-8, neutrophil elastase and ECP, and reduces microvascular leakage. Such anti-inflammatory effects in patients with COPD have previously been shown for the PDE4 inhibitor BAY 19-8004, although treatment with this compound was not associated with an effect on cellular inflammation. ${ }^{27}$ Lactoferrin levels were not significantly changed by roflumilast. However, the effect size was of the same order as for the other inflammatory parameters studied, which may indicate that the signal to noise ratio was too large for lactoferrin in our study with a relatively small sample size.

In addition to anti-inflammatory activity, we have shown that roflumilast improves both pre- and post-bronchodilator $\mathrm{FEV}_{1}$ in the same patients with COPD. This finding confirms recently reported data that roflumilast provides improvement in $\mathrm{FEV}_{1}$ of about $100 \mathrm{ml}$ together with a $34 \%$ reduction in the number of exacerbations in patients with lung function that is poorly reversible to bronchodilators. ${ }^{18}$ This improvement in $\mathrm{FEV}_{1}$ may in part be explained by the parallel reduction in the number and activation status of neutrophils and eosinophils in induced sputum samples of these patients with COPD.

A large proportion of patients experienced adverse events during roflumilast and placebo treatment, which is in line with previous studies. ${ }^{18}$ The most frequently encountered adverse events during roflumilast treatment were diarrhoea and headache, which are typically PDE4-related and part of the known side effect profile of roflumilast. All adverse events were transient and none of the patients experienced a serious adverse event. Although three patients discontinued the study because of adverse events during roflumilast treatment, these events resolved on withdrawal of the study medication. Whether roflumilast could be tolerated by these patients using a gradual increase in the dose was not investigated in this study.

The present study has potential limitations. First, patients with sputum neutrophils $\geqslant 45 \%$ were included in the study to ensure that there would be room for improvement in sputum neutrophils during treatment. Ninety-five percent of exsmokers with COPD had sputum neutrophilia of this magnitude and only two patients were excluded from participating in the study because of a lower percentage of neutrophils. It is therefore likely that our results can be generalised to most patients with COPD. Second, it has been suggested recently that a window of at least 6 months should be considered to evaluate the effect of treatment in COPD. ${ }^{28}$ Remarkably, even though our patients were treated for only 4 weeks, the present results show a clear treatment effect within this short time, as has been demonstrated previously for roflumilast. ${ }^{18}$ The treatment effect was corrected for variation during placebo treatment. During placebo treatment, a relative worsening of inflammation was observed as opposed to a relative attenuation during roflumilast treatment, resulting in a mean overall difference between roflumilast and placebo which was significant for various cellular and soluble markers of inflammation. Furthermore, the statistical analyses showed that there was no carry-over effect from the first period to the second period of treatment. Finally, the effect of possible confounders-such as smoking status and previous inhaled steroid usage — on roflumilast treatment could not be assessed because of the limited sample size. In order to investigate these effects and to examine whether the antiinflammatory effect of roflumilast is causally related to the improvement in lung function, prospective trials with a larger sample size should be performed.

How can the present results be explained? Roflumilast is a new oral once-daily administered inhibitor targeting PDE4. In patients with COPD, systemically available treatment may interact with pulmonary as well as systemic inflammation, both of which are present in COPD. ${ }^{14}$ Systemic effects of roflumilast associated with the initiation of inflammation can therefore be anticipated. TNF $\alpha$ is a major product of mononuclear leucocytes in the circulation which is regulated by $\mathrm{CAMP}^{15}$ and is involved in upregulation of the adhesion molecule E-selectin on vascular endothelium. ${ }^{29}$ Selectin-mediated adhesion of leucocytes to the vascular endothelium is a key early event in the initiation of inflammatory responses. ${ }^{29}$ Interestingly, increased levels of Eselectin in serum have been found in patients with COPD. ${ }^{9}$ In the present study, PDE4 inhibition by roflumilast was associated with a slight reduction in TNF $\alpha$ release following ex vivo stimulation of whole blood cells. However, E-selectin levels in serum were unchanged during roflumilast treatment. This may indicate either that the reduction in TNF $\alpha$ was too small to exert an effect on the expression of adhesion molecules or that the ex vivo release of TNF $\alpha$ by whole blood cells does not predict E-selectin release.

Microvascular leakage is regulated through the formation and closure of intercellular gaps between endothelial cells which facilitate the extravasation of fluid, macromolecules and cells. ${ }^{30}$ Increased levels of cAMP decrease intercellular gap formation and permeability, thereby restoring the integrity of the pulmonary endothelial barrier. ${ }^{30}$ In pulmonary endothelial 
monolayers cultured in vitro, induced hyperpermeability can be reduced by PDE3 and PDE4 inhibitors. ${ }^{31}$ The finding that $\alpha_{2}$ macroglobulin levels in sputum supernatant, a marker of microvascular leakage, ${ }^{32}$ were reduced by roflumilast suggest that in vivo inhibition of PDE4 also leads to restoration of the endothelial barrier. Apparently, this resulted in non-differential attenuation of cell extravasation from the circulation, as shown by a reduction in absolute cell counts for neutrophils, eosinophils, macrophages and lymphocytes in sputum without an effect on cell differential counts. These effects are not observed only in sputum samples, but also in bronchial biopsy specimens. ${ }^{25}$ Several studies have shown that the level of inflammation within the airways is associated with lung function in patients with COPD. ${ }^{33}{ }^{34}$ It is likely that attenuation of airways inflammation by roflumilast is one of the mechanisms underlying the observed improvement in lung function. Although a direct effect of PDE4 inhibition on smooth muscle relaxation cannot be excluded, ${ }^{12}$ this does not seem a likely explanation for the observed improvement in lung function because it has been shown that a single dose of PDE4 inhibitor does not provide bronchodilation. ${ }^{27}{ }^{35}$

Extensive in vitro and in vivo studies in animals have shown that inhibition of PDE4 increases the intracellular concentration of CAMP, leading to broad anti-inflammatory and immunomodulatory effects. ${ }^{15}{ }^{16}$ Indeed, in our study, the activity of several types of inflammatory cells was suppressed following roflumilast, as shown by large reductions in the levels of IL-8, neutrophil elastase and ECP. Although lactoferrin levels were not significantly reduced by roflumilast, the effect size was of the same order as for the other soluble markers. Alternatively, it could be speculated that PDE4 inhibition selectively affects the degranulation of azurophilic granules in neutrophils containing neutrophil elastase rather than in the specific granules containing lactoferrin. ${ }^{36}$ Because the submucosal glands, as well as neutrophils, are a major cellular source of lactoferrin production, an inhibitory effect of treatment on lactoferrin release by neutrophils may have been masked.

Our data have important clinical implications. At present the recommended treatment for COPD consists of bronchodilators for symptom relief with the addition of inhaled corticosteroids for more severe disease. ${ }^{137}$ Inhaled steroids have only limited effects on airway inflammation and lung function (decline) in patients with COPD. ${ }^{10}{ }^{38}{ }^{39}$ Roflumilast treatment in COPD improves not only lung function and health status, ${ }^{18}$ but also reduces the rate of mild exacerbations as judged from an increase in bronchodilator use and symptoms. ${ }^{18}$ This may be associated with reduced airway inflammation, as observed in our study.

In summary, our results support the hypothesis that roflumilast treatment has anti-inflammatory effects in patients with COPD. Whether such treatment also reduces airway remodelling, the progressive decline in $\mathrm{FEV}_{1}$ and the associated mortality risk in patients with COPD remains to be examined in long-term follow-up studies.

\section{ACKNOWLEDGEMENTS}

The authors thank Dr Kathy B Thomas and Dr Angela Schilling (Medical Writing, ALTANA Pharma AG, Konstanz, Germany) for helpful suggestions during the preparation of the article.

\section{Authors' affiliations \\ Diana C Grootendorst, Stefanie A Gauw, Renate M Verhoosel, Peter J Sterk, Pieter S Hiemstra, Klaus F Rabe, Department of Pulmonology, Leiden University Medical Center, Leiden, The Netherlands Jeannette J Hospers, Dirk Bredenbröker, Thomas D Bethke, ALTANA Pharma AG, Konstanz, Germany}

This study was financially supported by ALTANA Pharma AG, Konstanz, Germany. The study was designed by DCG, PJS, DB, TDB, PSH and KFR.
Data collection was performed by DCG, SAG and RMV. Altana monitored all collected data. Statistical analysis was performed by DCG, PJS, PSH and KFR and confirmed by an independent statistician (Dr G Rippin, Omnicare Clinical Research, Biometrics International). DCG, PJS, PSH and KFR interpreted the data and wrote the manuscript, which was subsequently discussed with and approved by ALTANA. All investigators and ALTANA agreed upon submission of the manuscript to Thorax.

Competing interests: DCG, SAG and RMV have no declared conflict of interest. The Department of Pulmonology, and thereby PJS (staff member), PSH (staff member) and KFR (head of the department), has received grants from ALTANA Pharma, Novartis, Bayer, AstraZeneca, Pfizer, MSD, Exhale Therapeutics, Boehringer Ingelheim, Roche and GSK in the years 2001-6. PSH has participated as a speaker in various meetings co-financed by various pharmaceutical companies. KFR has been a consultant, participated in Advisory Board Meetings and received lecture fees from AstraZeneca, ALTANA Pharma, MSD and GSK. KFR holds no stock or other equities in pharmaceutical companies. JJH, DB and TDB are employees of ALTANA Pharma.

\section{REFERENCES}

1 Rabe KF, Hurd S, Anzueto A, et al. Global initiative for Chronic Obstructive Lung Disease (GOLD). Global strategy for the diagnosis, management, and prevention of chronic obstructive pulmonary disease: GOLD executive summary. Am J Respir Crit Care Med 2007;176:532-55.

2 Hogg JC. Pathophysiology of airflow limitation in chronic obstructive pulmonary disease. Lancet 2004;364:709-21.

3 Keatings VM, Barnes PJ. Granulocyte activation markers in induced sputum: comparison between chronic obstructive pulmonary disease, asthma, and normal subjects. Am J Respir Crit Care Med 1997;155:449-53.

4 Wouters EF, Creutzberg EC, Schols AM. Systemic effects in COPD. Chest 2002;121(5 Suppl):127-30S.

5 Donaldson GC, Seemungal TA, Patel IS, et al. Airway and systemic inflammation and decline in lung function in patients with COPD. Chest 2005; 128:1995-2004.

6 Keatings VM, Collins PD, Scott DM, et al. Differences in interleukin-8 and tumor necrosis factor-a in induced sputum from patients with chronic obstructive pulmonary disease or asthma. Am J Respir Crit Care Med 1996;153:530-4

7 Fujimoto K, Kubo K, Yamamoto H, et al. Eosinophilic inflammation in the airway is related to glucocorticoid reversibility in patients with pulmonary emphysema. Chest 1999; 115:697-702

8 Gan WQ, Man SF, Senthilselvan A, et al. Association between chronic obstructive pulmonary disease and systemic inflammation: a systematic review and a meta-analysis. Thorax 2004;59:574-80.

9 Riise GC, Larsson S, Lofdahl CG, et al. Circulating cell adhesion molecules in bronchial lavage and serum in COPD patients with chronic bronchitis. Eur Respir J 1994;7:1673-7

10 Sutherland ER, Allmers H, Ayas NT, et al. Inhaled corticosteroids reduce the progression of airflow limitation in chronic obstructive pulmonary disease: a meta-analysis. Thorax 2003;58:937-41.

11 Barnes NC, Qiu YS, Pavord ID, et al. Antiinflammatory effects of salmeterol/ fluticasone propionate in chronic obstructive lung disease. Am J Respir Crit Care Med 2006;173:736-43

12 Grootendorst DC, Rabe KF. Selective phosphodiesterase inhibitors for the treatment of asthma and chronic obstructive pulmonary disease. Curr Opin Allergy Clin Immunol 2002;2:61-7.

13 Lipworth BJ. Phosphodiesterase-4 inhibitors for asthma and chronic obstructive pulmonary disease. Lancet 2005;365:167-75.

14 Essayan DM. Cyclic nucleotide phosphodiesterases. J Allergy Clin Immunol 2001;108:671-80.

15 Hatzelmann A, Schudt C. Anti-inflammatory and immunomodulatory potential of the novel PDE4 inhibitor roflumilast in vitro. J Pharmacol Exp Ther 2001;297:267-79.

16 Bundschuh DS, Eltze M, Barsig J, et al. In vivo efficacy in airway disease models of roflumilast, a novel orally active PDE4 inhibitor. J Pharmacol Exp Ther $2001 ; 297: 280-90$.

17 Wollin L, Bundschuh DS, Wohlsen A, et al. Inhibition of airway hyperresponsiveness and pulmonary inflammation by roflumilast and other PDE4 inhibitors. Pulm Pharmacol Ther 2006;19:343-52.

18 Rabe KF, Bateman ED, O'Donnell D, et al. Roflumilast-an oral antiinflammatory treatment for chronic obstructive pulmonary disease: a randomised controlled trial. Lancet 2005;366:563-71.

19 American Thoracic Society. Standardization of spirometry, 1994 update. Am J Respir Crit Care Med 1995;152:1107-36.

20 Quanjer P, Tammeling GJ, Cotes JE, et al. Lung volumes and forced ventilatory flows. Eur Respir J 1993;6(Suppl 16):5-40.

21 in't Veen J, De Gouw H, Smits HH, et al. Repeatability of cellular and soluble markers in induced sputum from patients with asthma. Eur Respir J 1996:9:2441-7.

22 Grootendorst DC, van den Bos JW, Romeijn JJ, et al. Induced sputum in adolescents with severe stable asthma. Safety and the relationship of cell counts and eosinophil cationic protein to clinical severity. Eur Respir J 1999;13:647-53. 
23 Schoonbrood D, Lutter R, Habets F, et al. Analysis of plasma-protein leakage and local secretion in sputum from patients with asthma and chronic obstructive pulmonary disease. Am J Respir Crit Care Med 1994;150:1519-27.

24 Smits HH, Grunberg K, Deriik RH, et al. Cytokine release and its modulation by dexamethasone in whole blood following exercise. Clin Exp Immunol 1998:111:463-8.

25 Gamble E, Grootendorst DC, Brightling $\mathrm{CE}$, et al. Anti-inflammatory effects of the phosphodiesterase 4 inhibitor cilomilast (Ariflo) in chronic obstructive pulmonary disease. Am J Respir Crit Care Med 2003;168:976-82.

26 Grootendorst DC, Gauw SA, van der Veen $\mathrm{H}$, et al. The need of analysing induced sputum absolute cell counts in addition to cell percentages in COPD [abstract]. Eur Respir J 2004;24(Suppl 48):306s.

27 Grootendorst DC, Gauw SA, Benschop N, et al. Efficacy of the novel phosphodiesterase-4 inhibitor BAY 19-8004 on lung function and airway inflammation in asthma and chronic obstructive pulmonary disease (COPD). Pulm Pharmacol Ther 2003;16:341-7.

28 Celli B. COPD, inflammation and its modulation by phosphodiesterase 4 inhibitors: time to look beyond the $\mathrm{FEV}_{1}$. Chest 2006;129:5-6.

29 Romano SJ. Selectin antagonists: therapeutic potential in asthma and COPD. Treat Respir Med 2005;4:85-94.

30 Moore TM, Chetham PM, Kelly JJ, et al. Signal transduction and regulation of lung endothelial cell permeability. Interaction between calcium and CAMP. Am J Physiol 1998;275:L203-22.

31 Suttorp N, Ehreiser P, Hippenstiel S, et al. Hyperpermeability of pulmonary endothelial monolayer: protective role of phosphodiesterase isoenzymes 3 and 4 . Lung 1996;174:181-94.
32 van Rensen EL, Hiemstra PS, Rabe KF, et al. Assessment of microvascular leakage via sputum induction. The role of substance $P$ and neurokinin $A$ in patients with asthma. Am J Respir Crit Care Med 2002;165:1275-9.

33 di Stefano A, Capelli A, Lusuardi $M$, et al. Decreased T lymphocyte infiltration in bronchial biopsies of subjects with severe chronic obstructive pulmonary disease. Clin Exp Allergy 2001;31:893-902.

34 di Stefano A, Capelli A, Lusuardi $M$, et al. Severity of airflow limitation is associated with severity of airway inflammation in smokers. Am J Respir Crit Care Med 1998;158:1277-85.

35 Grootendorst DC, Gauw SA, Baan R, et al. Does a single dose of the phosphodiesterase 4 inhibitor, cilomilast $(15 \mathrm{mg})$, induce bronchodilation in patients with chronic obstructive pulmonary disease? Pulm Pharmacol Ther 2003; 16:115-20

36 Faurschou $M$, Borregaard N. Neutrophil granules and secretory vesicles in inflammation. Microbes Infect 2003;5:1317-27.

37 Siafakas NM, Vermeire P, Pride NB, et al. Optimal assessment and management of chronic obstructive pulmonary disease (COPD). The European Respiratory Society Task Force. Eur Respir J 1995;8:1398-420.

38 Gizycki MJ, Hattotuwa KL, Barnes N, et al. Effects of fluticasone propionate on inflammatory cells in COPD: an ultrastructural examination of endobronchial biopsy tissue. Thorax 2002;57:799-803.

39 Hattotuwa KL, Gizycki MJ, Ansari TW, et al. The effects of inhaled fluticasone on airway inflammation in chronic obstructive pulmonary disease: a doubleblind, placebo-controlled biopsy study. Am J Respir Crit Care Med 2002;165:1592-6.

\section{LUNG ALERT}

Folate metabolism gene polymorphisms may influence lung cancer prognosis

$\Delta$ Matakidou A, el Galta R, Rudd MF, et al. Prognostic significance of folate metabolism polymorphisms for lung cancer. Br J Cancer 2007;97:247-52.

A berrant DNA methylation is a common feature of human neoplasia, including lung cancer. Folate metabolism pathway variants affect DNA methylation and tumour suppressor genes and may impact tumour behaviour. In this study the association between selected polymorphic variants of folate metabolism genes and overall survival of 619 Caucasian female patients with lung cancer was assessed.

Patients were included from the Genetic Lung Cancer Predisposition Study (GELCAPS) with non-small cell and small cell lung cancer at variable staging following standard UK management regimes. Associations between survival and clinical and demographic variables were assessed with overall survival as the primary endpoint.

A reduced overall survival was observed for single polymorphisms of MTHFS, MTHFR and MTRR genes. Specifically, associations with MTHFS Thr202Ala were related to reduced survival for all lung cancers for heterozygosity, homozygosity and carrier status. Carrier status for MTRR Ser175Leu was associated with a poorer outcome in all lung cancers, and homozygosity for the polymorphism MTHFR Ala222Val in small cell lung cancer. Carriers of MTHFR Arg594Gln with non-small cell lung cancer had a slightly longer overall survival. Staging and histology, both very important prognostic indicators, had no correlation with polymorphisms tested.

This study provides evidence for associations between survival and variation in three genes of folate metabolism; however, some of the associations may be false positives due to the methods used. Further genetic studies are needed to truly assess the influence of folate metabolism gene polymorphisms on clinical outcomes of survival and prognosis of lung cancer. 